\title{
LA LIBERTAD INTERIOR EN MONTAIGNE
}

\section{ANTONIO GómEZ ROBLEDO}

InSTTTUTO DE INVESTIGACIONES FiLOSÓFICAS

UNAM

Por muchos años que pasen no pasarán jamás las palabras con que Alfonso Reyes, al saludar la obra virgiliana, se refirió en general al destino de las obras del espíritu, las cuales, al desprenderse de su autor, viven por cuenta propia, y haciéndose a la mar del mundo y de la historia, "corren las sirtes a su modo".

De la obra escrita lo dijo sobre todo, a lo que creo, nuestro añorado humanista, pero más allá aún y hasta donde se me alcanza, puede decirse de toda idea en general, una vez que ha sido proferida por su autor o inventor. Una vez alumbrada, una idea no es como una batalla, por ejemplo, circunscrita para siempre dentro de cierto marco espaciotemporal, sino que se expande en virtualidades siempre nuevas e imprevistas y que pueden ser literalmente infinitas.

Tal acontece puntualmente, según creo, con la sentencia délfica: $\gamma \nu \bar{\omega} \theta \iota$ $\sigma \alpha v \tau o ́ \nu$, nosce te ipsum, "conócete a ti mismo", que fue el origen de la vocación de Sócrates, refrendada por su muerte heroica, y que más allá de él, y pese a su total agrafismo, ha fecundado hasta hoy la filosofia occidental. Es una larga historia, de ningún modo circunscrita a los llamados convencionalmente socráticos mayores o menores, sino que desemboca propiamente en el ego fenomenológico trascendental de Husserl, cuando no en el Dasein de Heidegger, o ¿qué sé yo? en estuarios más próximos aún a nosotros.

De esta larga historia, y por razones puramente personales, con lo que no estoy obligado a decir más, pláceme destacar el segmento que va, según el título de la conocida obra de Fortunato Strowski, de Montaigne a Pascal, un segmento rebosante de ideas y vivencias de todo género, y por ello mismo, extraordinariamente animado y conflictivo. Con lo cual, y por no abundar más en consideraciones preambulares, comencemos por el término de arranque (el término a quo de los antiguos) o sea por Montaigne.

Miguel Eyquem López, señor de Montaigne, nació el 28 de febrero de 1533, de Pedro Eyquem, de linajuda familia del Perigord, y de Antonia López, rica hembra de una familia de judíos españoles que a raíz de la expulsión de los de su raza por los reyes católicos, se establecieron primero en Portugal y 
más tarde en Toulouse y en Burdeos. Con el tiempo y para evitar dificultades, Antonia dejó la religión de Moisés para abrazar la religión reformada, aunque su marido siguió siendo católico. Por último, y en cuanto a los hijos de tan heterogéneo connubio (integrados tal vez en la vida íntima, de la que nada sabemos) parecen haberse repartido entre el padre y la madre, en lo relativo a la fe religiosa. En lo que ve a Miguel, al percatarse de que en la ambiguiedad familiar lo mejor era una definición precisa, hizo profesión solemne de fe católica ante el Parlamento de París en 1561, y en esta decisión perseveró hasta el día de su muerte.

Su primera educación fue de lo más extraño, a tal punto que puede calificarse de caso único en la historia. Pedro Eyquem, deseando ver a su hijo sobresalir en todo en sabiduría clásica, urdió para el niño Miguel un régimen de completo aislamiento, dentro del cual, y antes que empezara a hablar, le puso por tutor a un preceptor alemán, experto en lengua latina e ignorante del francés, con el fin, en suma, de que el infante recibiera el latín como lengua materna. Así fue hasta que, a los diez años de su edad, su padre hubo de enviarle a la escuela común a aprender el francés, pero con la cultura clásica a cuestas, o si a tanto no llegare, con su llave y su secreto.

No obstante haber sido en aquellos momentos el colegio de Guyana uno de los mejores de Francia, nada aprendió allí Miguel, según lo dice él mismo; nada sino la persuasión que se formó de que el saber auténtico (así nos lo enseñaron los griegos) no es ninguna memorización de lecciones muertas, sino un fruto laborioso y vital del espíritu, tal y como tiempo después lo dejó consignado él mismo:

Saber de memoria no es saber (savoir par coeur n'est pas sapoir) sino encomendar a la memoria lo que hemos oído.

Con el tiempo, a lo que se cree, estudió derecho en Toulouse, por ser profesión requerida para los altos cargos públicos, como era, entre otros, el de consejero del Parlamento de Burdeos, que Montaigne desempeñó de 1557 a 1570, fecha en que lo vendió para entregarse de lleno a las letras. En 1581, por último, y mientras se hallaba viajando por Italia, único viaje en largo que efectuó en su vida, fue nombrado alcalde de Burdeos, cargo que sirvió, por lo que puede saberse, durante cuatro años.

En su vida privada, Montaigne siguió el camino de toda carne al contraer matrimonio con Francisca de Chassaigne, un matrimonio de razón, a la larga los mejores, y que hubiera podido eventualmente dar lugar a un hogar feliz, de no haber sido por la negra suerte que hizo presa en él. 'Nacen seis hijas -escribe Juan José Arreola - pero cinco mueren prematuras. Esta desdicha, unida a la carencia de un heredero masculino, oscurece el matrimonio 
de Montaigne y lo convierte en una de las uniones más distanciadas y frías que registra la historia de la convivencia humana. ${ }^{\text {l }}$

De esta infelicidad conyugal vino a resarcirle, en parte por lo menos, la amistad amorosa que en la postrera etapa de su vida, bien cumplidos los 56 años, tuvo Montaigne por Mlle. Marie de Gournay, a quien nuestro pensador llegó a llamar “mi hija adoptiva, amada con afecto más que paternal”. A ella, a su desvelo por la gloria del hombre que fue su pasión y su maestro, debemos la edición monumental y póstuma de los Ensayos, prácticamente la que manejamos hasta el día de hoy.

Tanto su hogar desierto, así por la muerte precoz de la prole como por la inestabilidad política de Francia, desgarrada por las guerras de religión, con un salvajismo atroz entre quienes profesaban seguir el evangelio de Jesucristo, por todo esto, en suma, amén de otros factores aún, determinó Montaigne dar de mano a su vida pública para retirarse al diálogo consigo mismo y con los grandes espíritus del pasado, según lo hizo constar en la declaración latina de 1571 , inscrita en las paredes de su biblioteca, y que iba por el tenor siguiente:

En el año del Señor de 1571, a los 38 años de su edad, Miguel de Montaigne (Michael Montanus) agobiado hace mucho de la esclavirud de las cortes y las funciones públicas, y estando aún en buena salud (dum se integer) retírase al seno de las vírgenes sapientes, donde en paz y seguridad espera pasar el resto de su vida, consagrado en adelante a su ocio, libertad y tranquilidad.

He ahí un manifiesto militante de la vita contemplativa, y que su autor promulgó en el tercer piso de la torre construida por su padre. Allí pasó los años que fueron los más suyos, en soledad absoluta, y en el seno de libros dispuestos en una estantería circular. En aquel recinto dio amplio vagar a sus meditaciones, sin otro horizonte que el descrito por nuestro autor en el siguiente pasaje:

Veo abajo el jardín, el corral, el patio y la mayor parte de las dependencias de la casa. Allí hojeo un libro, luego otro, sin orden ni propósito, al azar. Ya divago, ya anoto y dicto, paseando, los sueños que aquí veis: mes songes que voici. ${ }^{2}$

Los sueños que aquí veis constituyen, según el comentario unánime, una de las obras más ricas y complejas de la literatura universal. Según lo vio Azorín, "Montaigne no es un filósofo de lo abstracto, de lo confuso, de lo oscuro, de lo ininteligible, de lo inescrutable, de lo fantástico. Montaigne es un filósofo de lo concreto, de lo menudo, de lo trivial, del detalle prosaico, de lo que vemos y palpamos todos los días en la casa y en la calle."

1 Montaigne, Ensayos escogidos, UNAM, México, 1978, p. 10.

2 Ensayos, III, 3. 
Ésta es la filosofía de los Ensayos, y en esto creo que hay consenso unánime, por mucho que continúe discutiéndose si Montaigne fue estoico o escéptico, o simplemente partidario de la suspensión del juicio o de la libertad interior, sobre todo lo cual volveremos más tarde.

Antes de seguir adelante en la cuestión de fondo, hagamos un breve paréntesis y preguntémonos sobre el porqué del término Ensayos, cuya genealogía semántica ha trazado Juan José Arreola en la página que copiamos sin mayor comentario:

"Cuando Enrique de Navarra pasó dos días en el castillo de Montaigne, quiso dar a su anfitrión una prueba de confianza, y se negó a que los manjares fueran ensayados en la mesa." Probados o degustados por el copero real, por lo que ensayo sería degustación o gustus, voz latina que hasta hoy suele traducirse como ensayo, el que hace el buen catador para apreciar la calidad del licor. Montaigne, por su parte, desentendiéndose de esta semántica, aunque sin repudiarla, adelanta otra interpretación del género literario inaugurado por él mismo en la historia de la literatura. Así, entre otros, en el siguiente pasaje:

Toda esta pedacería (fricassée) que emborrono, no es más que el registro de los ensayos de mi vida. ${ }^{3}$

Donde ensayo, como puede verse, no quiere decir sino experiencia, y no ejercicio preliminar de un acto, como será después. Este otro sentido aparece tal vez en este paso:

Si mi alma pudiera asentar firmemente el pie, me resolvería en lugar de ensayarme; pero está siempre en prueba y aprendizaje.

No otra cosa consiente la inestabilidad humana, y por esto dice Montaigne, líneas arriba del pasaje citado, que el mundo entero, con emimente inclusión del hombre, es un balanceo perenne, y que la constancia misma no es sino un movimiento más lánguido. Y estando todo como está, el sujeto y el objeto, sumidos en un perpetuo flujo heraclitano, el oficio de nuestro autor es el que expresa él mismo en esta sentencia de profundidad insondable:

Yo no pinto el ser, sino que pinto el tránsito (el devenir diríamos hoy); y no el tránsito de una edad a otra o, como dice el pueblo, de siete en siete años, sino de día en día, de minuto en minuto, pues tengo de acomodar mi historia a la hora misma en que la refiero, ya que podría cambiar un momento después. Es la mía un registro de diversos y mudables sucesos, de fantasías irresueltas y contrarias

3 Ensayos, III, 3.

4 Ensayos, III, 2. 
si viene al caso, ya sea porque me convierta en otro yo, o porque aprehenda los objetos por otras circunstancias y consideraciones. ${ }^{5}$

Éste es, pues, el ensayo montaniano, la eterna confrontación del yo con el mundo, uno y otro en perpetua mudanza, o como dijo él mismo antes, el alma humana en continuo aprendizaje. Si de esta confrontación puede o no surgir alguna doctrina permanente, lo veremos después, mas por lo pronto dejemos constancia de que este frotamiento entre hombre y mundo no es sólo el que se da entre Miguel de Montaigne y su circunstancia, sino entre el hombre y el mundo en general, ya que, según lo dice el propio Montaigne, "cada hombre lleva consigo la forma entera de la humana condición". Ahora bien, y en virtud de esta universalización de las experiencias particulares de Montaigne, ha podido verse en él a uno de los precursores de la antropología filosófica en el sentido que le han dado Scheler, Cassirer y Groethuysen.

"Una cosa maravillosamente varia, diversa y ondulante (así lo dice Montaigne en el principio de sus Ensayos) es el hombre, y es bien difícil arraigar en él un juicio constante y uniforme." No por esto, sin embargo, ha de tener los mismos caracteres el juicio que al final formemos sobre esta criatura proteica y en movimiento continuo.

Sea de ello lo que fuere y antes de terminar con el discurso de su vida, hay algo que importa aclarar bien desde este momento, y es el punto de que a despecho de su naturaleza igualmente varia y ondulante (de otro modo no habría compartido la condición humana), no se apartó Montaigne en ningún momento de la religión tradicional, no obstante estar su país, y aun su propia familia, en una continua y desgarradora escisión entre la religión atávica y la religión reformada. Fue una situación, por lo demás, que no se resuelve definitivamente sino a la muerte de Enrique III, cuando Enrique IV, el jefe del partido reformista, abandona su parcialidad y su religión al empuñar el cetro de rey de Francia. De no haber sido por este acto, Francia podría haber pasado a engrosar el número de Estados protestantes.

Si la conducta de Montaigne en este particular estuvo o no dictada por motivos políticos, no hay sino Dios que pueda saberlo. Para los hombres, que no podemos hacer otra cosa que registrar los hechos, es válido hasta hoy el siguiente juicio de André Cresson:

Montaigne se proclamó siempre católico. Vivió y murió como católico. Es algo no discutible, ni ha sido nunca discutido. ${ }^{6}$

De sus últimos momentos nos limitamos a copiar el relato de Pasquier:

5 Ibid.

6 A. Cresson, Montaigne, PUF, 1947, p. 66. 
Como sintiera aproximarse su fin, hizo decir la misa en su habitación, y en el momento en que el sacerdote procedía a la elevación del Corpus Domini, se incorporó sobre su lecho como pudo y con las manos juntas, y en este úlrimo acto dio su espíritu a Dios.?

\section{Meditatio mortis}

Pasemos ahora, y es por cierto nuestro principal cometido, a la filosofía de Montaigne, cuya exposición, hasta hoy, no ha sido nada fácil, por las razones que se verá en seguida.

La habilidad de un escritor, ha dicho Renan, consiste en tener una filosofia, con tal de esconderla. El público ha de ver los riachuelos, pero no las fuentes de que brotan, y oír los sonidos sin ver el instrumento que los produce.

Ahora bien, ninguna obra filosófica responde mejor a este programa que la de Montaigne, cuya filosofia no ha sido expuesta de manera explícita en parte alguna, pero sí implícita en pasajes numerosísimos, y es a éstos a los que debemos reducir, en la exegética, a cierto orden, congruencia y armonía. Todo esto, naturalmente, en la medida de lo posible, ya que serán siempre pensées détachées los que van surgiendo de la meditación vigorosa de aquel gentilhomme campagnard que nunca quiso endosar un hábito profesoral de ninguna especie.

Planteado así el problema, la primera evidencia que se ofrece a nuestros ojos es la de que Montaigne fue, ante todo y sobre todo, un pensador socrático, en razón precisamente de haber puesto por entero su energía intelectual y su vida misma al servicio del "conócete a ti mismo", la inscripción délfica que fue en Sócrates el origen y el alma de su vocación filosófica. "Los Ensayos, dice Ferdinand Brunetière, son la ilustración más brillante y la prueba más

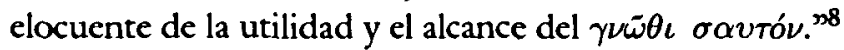

Aparte de que esta aseveración se justifica por la contextura misma de los Ensayos, un continuo examen del autor de sí mismo, abundan aún los testimonios directos de Montaigne en homenaje a la máxima socrática, entre otros el siguiente:

En los libros no busco sino un entretenimiento agradable, y si alguna vez me aplico a su estudio, no busco en ellos sino la ciencia que trata del conocimiento de mí mismo, y que me enseña a bien vivir y a bien morir."

A propósito del bien morir, tropezamos con el capítulo 20 del libro I de los Ensayos, uno de los más hermosos, y que lleva por título "Que filosofar

${ }^{7}$ Apud Cresson, op. cit., p. 18.

${ }^{8}$ Histoire de la litterature frangaise, I, p. 602, ed. 1921.

9 Ensayos, I, 10. 
es aprender a morir”. Antes de cualquier glosa, lo mejor será tal vez tener presente ante nosotros el primer párrafo:

Dice Cicerón que filosofar no es otra cosa que disponerse a la muerte. Lo que es tanto como decir que el estudio y la contemplación retiran en cierto modo nuestra alma fuera de nosotros, lo cual es cierto aprendizaje y semejanza de la muerte; o bien que toda la sabiduría y el discurso del mundo se resuelve al final en enseñarnos a no temer la muerte.

No deja de ser extraño, digámoslo para empezar, el que Montaigne, al citar a Cicerón, no cite la última fuente a que remite expresamente el escritor latino en el siguiente pasaje de las Tusculanas:

La vida entera del filósofo, en efecto, como lo dice el mismo (Sócrates-Platón) es una preparación a la muerte. ${ }^{10}$

Preparación o meditación, según el texto original: Tota enim philosophorum vita commentatio mortis est.

La última fuente, en efecto, de la célebre sentencia, se encuentra en el Fedón (67d) donde Sócrates, en el discurso de su último día, expresa la idea de que el ejercicio propio del filósofo es un desapego y separación del alma con respecto al cuerpo.

Sólo de este modo, según se expresa líneas arriba, podremos estar "unidos a entes semejantes a nosotros", a las Ideas, es decir, las que encarnan la única realidad verdadera.

De esta interpretación de la sentencia socrático-platónica se hace cargo Montaigne en el pasaje que estamos comentando; y en seguida, en apariencia de propia cuenta, pero en realidad con amplio arraigo en la tradición filosófica, añade la consideración de que el servicio mayor que podemos esperar de la filosofía es el de liberarnos del terror de la muerte. Sería largo seguirle por este camino, pero no podemos dejar de espigar aquí y allá pensamientos como el siguiente:

Puesto que no sabemos dónde nos espera la muerte, esperémosla dondequiera. La premeditación de la muerte es premeditación de la libertad. Quien ha aprendido a morir ha desaprendido a servir. El saber morir nos libera de toda sujeción y constricción. No hay ningún mal en la vida para quien ha comprendido bien que la privación de la vida no es un mal.

De Séneca directamente, el maestro mayor de Montaigne, vienen estos pensamientos, y lo más curioso es que Séneca mismo los consigna como una glosa de su mayor enemigo, Epicuro, pero así es. Oigámosle: 
Medita en la muerte, dice Epicuro, o mejor aún, en el tránsito a los dioses. El sentido es patente. Magnífica cosa es aprender a morir. Medita en la muerte; quien nos lo ha dicho, manda que se medite en la libertad. Quien aprendió a morir, deja de saber cómo se sirve, porque está por encima de todo poder. ¿Qué le importan la cárcel, los guardias, los encierros? Tiene libre la puerta. ${ }^{11}$

\section{Meditare mortem, qui hoc dicit, meditari libertatem iubet.}

Al terminar este magnífico capítulo, dice aún Montaigne:

¿Por qué el temor que tienes de tu último día, que no contribuye más a tu muerte que cualquiera de los días antes pasados? No es causa del cansancio el último paso, que se limita a declararlo. Todos los días van a la muerte, y a ella llega el último.

"La muerte nos toma, no nos arrebata": carpit nos illa, non corripit, añade por su parte Séneca. ${ }^{12}$

\section{Montaigne escéptico}

Con lo dicho baste para que podamos contar a Montaigne entre los viri socratici, pero esto no es suficiente, ya que la herencia se reparte, apenas muerto el maestro ateniense, en incontables denominaciones de diversos signos y a menudo contradictorios entre sí. De la nueva Academia, para no hablar sino de lo que más directamente nos concierne, surgió una de las ramas del escepticismo, y en Atenas también, al pasar por allí Zenón de Kitio, nació la Stoa. Ahora bien, hasta hoy se cree que una y otra corriente están presentes en Montaigne, según el testimonio, uno de tantos, de Abbagnano y Visalberghi:

El estoicismo y el escepricismo, aprendidos en los escritores antiguos, son las dos experiencias fundamentales con que espera conquistar la libertad espiritual. ${ }^{13}$

Montaigne mismo, por lo demás, se ha hecho cargo del problema en muchos pasajes, y sobre todo tal vez en el que por su importancia transcribimos:

Todo aquel que busca alguna cosa, colócase en una de estas tres posiciones: o dice que la ha encontrado, o que no es posible encontrarla, o que está aún en su búsqueda. Ahora bien, en estos tres géneros está repartida la filosofía, siendo su fin el de indagar por la verdad, la ciencia y la certeza. Los periparéricos, epicúreos y otros aún, piensan haberla encontrado, a cuyo efecto han constituido

11 Cartas a Lucilio, 26.

12 Ad Lucilium, 120.

13 A.V., Historia de la pedagogla, FCE, México, 1975, p. 232. 
las ciencias que hemos recibido nosotros como ciertas. Clitómaco, Carnéades y los académicos han desesperado de esta pesquisa y han decidido que la verdad no puede concebirse por los medios a nuestro alcance... Pirrón y otros escépticos dicen a su vez que ellos, por su parte, están aún en busca de la verdad.

La exposición anterior está tomada sustancialmente de las Hipotiposis de Sexto Empírico $(I, 1)$ para el cual la filosofía ha revestido históricamente estas tres formas: la filosofía dogmática, que afirma estar en posesión de la verdad; la filosofía académica, para la cual la verdad estaría por encima de nuestra inteligencia, y la filosofía escéptica, siempre en procura de la verdad, pero sin haber podido encontrarla hasta ahora.

Como podrá verse por este y otros pasajes que no es posible aducir aquí, el escepticismo de Montaigne (empecemos por él, por tratarse de una posición preparatoria) no es del tipo del escepticismo antiguo, el de Carnéades, y antes de él Gorgias, para el cual lo único que existe es la nada, y si algo existiera, no podríamos conocerlo, como tampoco podríamos comunicarlo. Nihilismo radical, metafísico y epistemológico, reactualizado en la ćpoca de Montaigne, por lo que sabemos, en la persona del médico portugués Francisco Sánchez, quien enseñó en Toulouse medicina y filosofía, y que dejó entre sus escritos uno con este título: Quod nibil scitur. Trátase en realidad de una posición dogmática, del mismo género, aunque de signo contrario, del que se imagina estar en plena posesión de la verdad.

El escepticismo de Montaigne es apenas la suspensión del juicio entre las distintas posiciones dogmáticas, y por esto llama a los escépticos, como Pirrón, epechistes, un neologismo de su invención, o sea los que, como dirá más tarde Edmundo Husserl, practican la epoxé, es decir la reducción fenomenológica por la que ponemos el mundo natural entre paréntesis. ${ }^{14}$

El escepticismo, que de suyo no quiere decir sino examen ( $\sigma \kappa \epsilon ́ \pi \tau o \mu \alpha \iota$, $\sigma \kappa \hat{\epsilon} \psi \iota \varsigma)$ no es sino una actitud preambular en la vida del espíritu, o como dijo Emerson en su célebre ensayo sobre Montaigne o el escéptico, una inevitable etapa en el desarrollo de toda inteligencia superior, y bajo esta luz, precisamente, enfoca a Montaigne como escéptico.

Tal es también, si no me engaño, la interpretación de Pascal, según la expone en su Entretien avec $M$. de Saci. A juicio de Pascal el Que sais-je? de Montaigne, colocado gráficamente entre los dos platillos de una balanza que, con las proposiciones contradictorias en cada platillo, están en perfecto equilibrio, habría que entenderlo del modo siguiente:

Sobre este principio giran todos sus discursos y todos sus Ensayos, con lo que destruye insensiblemente todo lo que pasa por ser lo más cierto entre los hombres, y no para establecer una certeza de que es enemigo, sino para hacer ver que

14 Ensayos, II, 12, p. 221, ed. Folio. 
siendo las apariencias iguales de una y otra parte, no puede saberse dónde fincar la creencia. ${ }^{15}$

La duda de Montaigne sería pues, en principio, una duda precautoria o metódica, como lo será, andando el tiempo, la duda cartesiana.

Hay, sin embargo, un momento en que la duda metódica parece desenlazar en una duda constitucional, en un escepticismo radical, y es en la Apología de Raimundo Sabunde, documento del que pasamos a ocuparnos.

\section{La Apologia de Raimundo Sabunde}

Raimundo Sabunde, español y catalán por más señas, pasó a Francia y acabó por avecindarse en Toulouse, donde enseñó medicina y teología. Entre sus admiradores estuvo Pedro Eyquem, quien pidió a su hijo Miguel que le tradujera la obra del teólogo catalán, intitulada Theologia naturalis. La traducción, publicada en 1569, señala la aparición de Montaigne como hombre de letras. Ahora bien, el libro parece haber seducido también al traductor, probablemente porque hasta donde sabemos quienes no hemos podido leerlo, la Teologla natural, o Libro de las criaturas o Libro del hombre (con estos tres títulos se le conoce) pretendía demostrar la verdad de la fe católica con apoyo en la razón natural y en la naturaleza del hombre, todo lo cual encajaba a la perfección con el designio que Montaigne se había trazado para su propia obra. Por lo que haya sido, en suma, el heche es que le dedicó por entero el capítulo XII del libro segundo de sus Ensayos, un capítulo de tal longitud que en cualquier edición cubre más de doscientas páginas. Es todo un tratado aparte, y si se me permite el parangón con la mayor de las Críticas kantianas, yo diría que en Montaigne es la Crítica de la razón natural, de sus límites, como en Kant, o más allá aún, de su impotencia, como espero hacerlo ver en lo que se dirá en seguida.

La apología de Raimundo Sabunde, en efecto, si hay que reconocerle este carácter, habrá de ser siempre cum grano salis. Después de haber confesado que hizo la traducción "porque no podía rehusar nada al mejor de los padres", procede Montaigne a formular un juicio general sobre una obra "cuyo fin es osado y valeroso, ya que lo que emprende es establecer y verificar contra los ateos, y nada más que por razones humanas y naturales, todos los artículos de la religión cristiana”. Por todo lo cual, según sigue diciendo nuestro autor, no parece creíble que un libro tan rico y tan hermoso (trop riche et trop beau) pueda haber sido escrito por un oscuro médico de Toulouse, pero sea quien haya sido el autor (Montaigne deja abierta la cuestión) tenemos allí algo así como "una quintaesencia extraída de santo Tomás de Aquino, ya que en verdad aquel

15 Pascal, Pléiade, la. ed., pp. 347-348. 
espíritu, lleno de una erudición infinita y de una sutileza admirable, fue el único capaz de albergar ideas semejantes".

Después del elogio, sin embargo, inmediatamente después, viene el primer ataque, y ataque frontal, contra la Theologia naturalis sive liber creaturarum, en los siguientes términos:

La primera reprensión de esta obra es la de que los cristianos hacen agravio a su causa al tratar de apoyar su creencia en razones humanas, siendo así que no puede provenir sino de la fe y de una inspiración particular de la gracia divina... Yo por mi parte no creo que los medios puramente humanos sean de ningún modo capaces de consumar una empresa tan divina y tan alta y que excede con mucho al entendimiento humano, como lo es la de descubrir la Verdad con que Dios, en su bondad, ha tenido a bien iluminarnos... Es la fe tan sólo la que puede abrazar vividamente y con certeza los altos misterios de nuestra religión. ${ }^{16}$

A mi humilde saber y entender, tenemos allí una profesión fideísta, en cuanto exaltación incondicional de la fe teologal, en detrimento de la razón humana; una crítica que, dicho sea de paso, afecta al propio Tomás de Aquino, por lo menos al autor de la Summa contra gentiles. Ahora bien, y si he decir francamente lo que siento, yo encuentro muy difícil conciliar este fideísmo con lo que por otra parte sabemos de la personalidad de Montaigne, por lo que no puedo descartar la hipótesis de que esta postura haya sido en él insincera, y que si la asumió habrá sido, con toda probabilidad, por precaverse del Santo Oficio. Es bien posible, en efecto, y por más que no pase de mera conjetura, que Montaigne haya tenido conocimiento de la condenación del concilio de Trento (1545-1563) del prólogo de la Theologia naturalis de Raimundo Sabunde, por su excesivo naturalismo en detrimento de la fe revelada. En esta hipótesis, todo se aclararía, y si no, estaríamos en presencia de la cuestión, hasta hoy irresoluta, de la compatibilidad o incompatibilidad del fideísmo de Montaigne con el resto de su obra. "Extraña apología, comenta André Cresson, la que apunta nada menos que a arruinar la autoridad de la razón en las mismas materias en que Sabunde busca su apoyo. $\$ 17$

Sea de todo ello lo que fuere, la Apología ofrece el gran interés de ser un resumen de la antropología de Montaigne, por lo que no podemos eximirnos de pasar por ella nuestros ojos, así sea summa per capita.

Lo primero que hace Montaigne, de entrada como si dijéramos, es poner al hombre en su lugar, "en el amplio seno de la naturaleza", para hacerle ver que, contra lo que se figura, está muy lejos de ser el amo y señor de la creación. Oigámosle:

16 Essais, II, 12, pp. 140-141, ed. Folio.

17 A. Cresson, Montaigne, PUF, Paris, 1947, p. 67. 
Consideremos, pues, al hombre solo, sin socorro ajeno, armado únicamente de sus propias armas y desprovisto de la gracia y el conocimiento divino que es todo su honor y su fuerza y el fundamento de su ser. Veamos qué puede exhibir con tan bella dotación. Hágaseme entender, por la fuerza de la razón, sobre qué fundamentos ha erigido esa gran ventaja que piensa tener sobre las demás criaturas, y quién ha podido persuadirle de que por su comodidad y servicio han sido creadas cosas tales como el admirable movimiento de la bóveda celeste, la eterna luz de los luminares que brillan sobre su cabeza y los temerosos movimientos del mar infinito, con todo lo demás así establecido y que perdura desde hace tantos siglos. ¿Es posible imaginar nada tan ridículo como el que esta mísera y deleznable criatura, que ni siquiera es dueña de sí, y que está expuesta a las ofensas de todo y de todos, se diga ama y emperatriz del universo, a pesar de que no está en su mano conocer la menor parte del mismo, y mucho menos imperar sobre él? Atribúyese el hombre el privilegio de ser en esta gran obra el único capaz de reconocer su belleza y partes, el único que puede dar gracias al Arquitecto y el único capaz de llevar cuenta y razón del mundo; mas iquién le ha sellado este privilegio? Que nos muestre las credenciales de este tan grande como noble cargo... Ni vamos a dar oídos a quien ha escrito: "iPara quién diremos que fue formado el mundo? Sin duda para los entes animales y dotados de razón, es decir los dioses y los hombres, pues que nada hay mejor que ellos?"18

Hay, además, otro factor que interviene en esta devaluación del hombre, y es la visión cerradamente aristotélico-medieval que tiene Montaigne del universo, con este nuestro mundo "sublunar" como el más despreciable de todos, y sobre el cual gravitan incondicionalmente los cuerpos celestes, "si tenemos en cuenta el dominio y poder que estos cuerpos ejercen no sólo sobre nuestras vidas y condiciones de nuestra fortuna, sino sobre nuestras mismas inclinaciones, discursos y voluntades, las cuales rigen ellos, pulsan y agitan a merced de sus influencias, si vemos que no ya cada hombre o cada rey, sino las monarquías e imperios de todo este bajo mundo, se mueven al impulso de los menores movimientos celestes".

Dios, en efecto, según una cita que hace Montaigne del poeta Manilio, ha hecho depender de los astros la vida y los actos de los hombres:

\section{Facta etenim et vitas hominum suspendit ab astris.}

¿Cómo es posible, nos preguntamos no sin asombro, que Montaigne haya podido prohijar tales inepcias en el siglo de Galileo y Copérnico? Más aún, se diría que en su astrología va más allá aun que Aristóteles, por cuanto que no sólo ve en los astros entes eternos e incorruptibles, sino que les adjudica "alma, vida y razón”, y llega a declarar que son sueños de la vanidad humana el hacer de la luna una tierra celeste, donde, como quiere Anaxágoras, hay

18 Essais, II, 12, p. 152, ed. Folio. La cita es de Cicerón, De natura deorum, II, 54. 
montañas y valles. De lo que deducimos, a nuestro humilde saber y entender, que Montaigne no pasó en cosmología de los primeros presocráticos, toda vez que Anaxágoras, el último presocrático, no vio en el sol sino una masa ígnea, por lo cual hubo de huir de Atenas para escapar a la acusación por crimen de impiedad. Para Montaigne, por el contrario, como para los antiguos atenienses, el astro rey parece ser un ente vivo, animado y pensante.

Traslademos aún, por su prominencia dentro del mismo contexto, el siguiente párrafo:

La presunción es nuestra dolencia natural y original. La más calamitosa y frágil de todas las criaturas es el hombre, y al mismo tiempo la más orgullosa. Siéntese y mírase alojado entre el fango y el estiércol del mundo, atado y clavado a la peor y más muerta y vil parte del universo; en el piso más hondo de la casa y el más alejado de la bóveda celeste, y no obstante, imaginativamente plántase por encima del círculo de la luna y pone el cielo por debajo de sus pies. ${ }^{19}$

Es patente, insistimos, en esta desestima del hombre, el peso de la física aristotélica, de la física, una vez más, y no de la metafísica, dentro de la cual la posesión del logos por parte del hombre le da una superioridad absoluta sobre el resto del universo. Todos los cuerpos reunidos no valen el menor de los espíritus, dirá más tarde Pascal: Tous les corps réunis ne valent pas le moindre des esprits. De esta intuición pascaliana no parece haberse hecho solidario Montaigne.

Pasando ahora del dominio de la naturaleza al dominio del espíritu, he aquí cómo plantea el problema el autor de los Ensayos:

Fáltame ver, en fin, si está en el poder del hombre el hallar lo que busca, y si la indagación en que se consume hace tantos siglos, ha podido enriquecerle con alguna nueva fuerza y alguna verdad sólida. ${ }^{20}$

Ahora bien, y aun antes de proceder, como lo hace, al recuento minucioso de las doctrinas filosóficas más conspicuas, anticipa Montaigne su desoladora conclusión en los términos siguientes:

Quien hable en conciencia creo que confesará que todo lo que hemos podido sacar en limpio después de tan larga pesquisa, es aprender a reconocer nuestra flaqueza. La ignorancia que por naturaleza está en nosotros, la hemos confirmado y comprobado después de largo estudio. A las gentes verdaderamente sabias les pasa lo que en el trigo a las espigas, que yérguense altaneras, la cabeza recta y orgullosa, mientras están vacías de grano, pero que agáchanse y humíllanse cuando están pletóricas. Pues de modo semejante los hombres que lo han ensayado e indagado

19 Essais, II, 12, p. 155, ed. Folio.

20 Essais, II, 12, p. 218, ed. Folio. 
todo, al no encontrar en este amasijo de doctrina y condición de tantas cosas diversas nada macizo y firme, sino sólo vanidad, han renunciado a su presunción y reconocido su condición natural.

De esta miserable condición de la mente humana, sigue diciendo Montaigne, dan testimonio los mayores filósofos de la antigüedad, comenzando por Sócrates, "el hombre más sabio que jamás ha existido y que, al ser interrogado sobre lo que sabía, respondió que sólo sabía que nada sabía”. Y pasando adelante, bastará con citar este pasaje de Cicerón:

Decían los antiguos, casi todos, que nada se conoce, nada se percibe, nada puede saberse, porque nuestros sentidos son limitados, nuestra mente débil y nuestra vida demasiado corta. ${ }^{21}$

La documentación de estos asertos la hace Montaigne en la revisión que lleva a cabo de las tres corrientes en que, según dijimos antes, divide él la filosofía: la filosofía dogmática, que se ostenta como descubridora de la verdad; la filosofía académica, según la cual la verdad está por encima de nuestra inteligencia, y la filosofía escéptica, que declara buscar la verdad sin haberla encontrado hasta ahora. Pues bien, y por diferentes que estas corrientes puedan parecer entre sí, al final todas ellas confluyen en el desencanto, como nos lo hace ver, una vez más, el propio Cicerón, el mejor espejo de la filosofía antigua, cuando nos confiesa que por más que haya de proseguir en el discurso filosófico, habrá de ser sin afirmar nada, buscando siempre, dudando a menudo y desconfiando de sí mismo. ${ }^{22}$

¿No es ésta, se pregunta Montaigne con toda razón, la actitud mental característica de la nueva Academia, y por más que Cicerón rechace en principio la doctrina de Arcesilao y Carnéades?

Así pues, termina diciendo Montaigne, de las tres sectas filosóficas generales, dos hacen profesión expresa de duda y de ignorancia, y en la tercera, la de los dogmáticos, es fácil ver que la mayoría no asumen la máscara de la certeza sino por salvar las apariencias. No han querido tanto establecer una certeza como hacernos ver hasta dónde han llegado en esta cacería de la verdad que los sabios imaginan más que conocen: quam docti fingunt, magis quam norunt.

Si inquirimos, en fin, por la raíz más profunda del escepticismo de Montaigne, no será difícil encontrarla en el viejo panta rei heraclitano, que permea por completo a quien, confesándose ondoyant et divers, de parmenídico no

21 Cicerón, Contra academicos, I, 12: Omnes pene veteres nibil cognosci, nihil percipi, nihil sciri posse dixerunt; angustos sensus, imbecillos an imos, brevia curricula vitae.

22 De divinatione, II, 3: Dicendum est, sed ita ut nibil affirmem, quacram omnia, dubitans plerumque et mihi diffidens. 
podía tener nada en absoluto. Recordemos cómo desde el principio de los Ensayos $(I, 14)$ nos ha dicho que él no pinta el ser sino el devenir: Je ne peints pas l'être; je peints le passage. No ha de extrañarnos, por ende, que al final de la Apologia de Raimundo Sabunde, termine con esta desoladora declaración:

Por último, no hay ninguna existencia constante, ni de nuestro ser ni del de los objetos. Todas las cosas mortales, entre ellas nuestro juicio, fluyen y ruedan de continuo, sin que pueda establecerse nada cierto de una a otra, por hallarse enjuiciador y enjuiciado en continuo movimiento y mudanza.

No tenemos comunicación alguna con el ser, porque toda naturaleza humana está siempre intermedia entre el nacer y el morir, no teniendo de sí más que una apariencia oscura y sombría y una opinión débil e incierta. Querer que el pensamiento aprehenda el ser (prendre l'être) es como querer abrazar el agua. Cuanto más el pensamiento pugne por aferrar lo que de su naturaleza fluye por doquier, tanto más perderá lo que se proponía retener y coger. Visto, pues, que todas las cosas están sujetas a pasar de uno a otro cambio, la razón, buscando una subsistencia real, se halla decepcionada al no dar con nada subsistente y permanente, ya que todo, o viene a ser sin ser aún del todo, o comienza a morir antes de nacer. ${ }^{23}$

Pascal no es un escéptico precisamente, más aún, censura repetidamente a Montaigne; y sin embargo, los críticos creen encontrar el influjo de la página montaniana que acabamos de transcribir en esta otra no menos hermosa de los Pensamientos:

Bogamos en un vasto medio, siempre inciertos y flotantes, empujados de un extremo a otro. Si damos con un término a que pensamos adherirnos y en que pensamos afianzarnos, titubea y nos abandona; y si lo seguimos, se nos escapa de las manos, se desliza y nos huye en una fuga eterna. Nada se detiene por nosotros. Es el estado que nos es natural, y sin embargo, el más contrario a nuestra inclinación. Ardemos en deseos de encontrar una sede firme y una base constante para edificar sobre ella una alta torre que se alce a lo infinito, pero nuestros cimientos se agrietan y la tierra se abre hasta los abismos.

"No busquemos, pues, punto de seguridad y firmeza... Nada puede fijar lo finito entre los dos infinitos que lo envuelven y le huyen. ${ }^{24}$ Los dos infinitos de Pascal, lo infinitamente grande en la infinita dilatación del universo, y lo infinitamente pequeño en la infinita divisibilidad de la materia.

Penetrado de estas ideas, Montaigne termina diciendo:

¿Qué será, por tanto, el ser verdadero? Lo eterno, es decir, lo que nunca nació ni tendrá jamás fin, y a quien el tiempo no aporta nunca ninguna mutación. El tiempo es cosa móvil, que aparece como en sombras, de materia corriente

24 Pensées, 72, Brunschwicg. 
y fluyente, sin adquirir nunca permanencia ni estabilidad. A él pertenecen estas palabras: antes, después, fue o será, las cuales muestran con evidencia que no es cosa que sea... Por lo cual es pecado decir de Dios, el único que es, que fue o que será... y por estos motivos ha de concluirse que sólo Dios es, no según medida alguna del tiempo, sino según una eternidad inmutable e inmóvil, no medida por el tiempo ni sujeta a ninguna declinación... QQué cosa tan vil y abyecta, dice Séneca, es el hombre que no se eleva por encima de la humanidad! ${ }^{25}$

El escepticismo de Montaigne, en conclusión, no para en un nihilismo dogmático, como el de Gorgías o el de la nueva Academia, o aún en la edad moderna, el de Francisco Sánchez (quod nibil scitur) sino que, como lo destaca Nicola Abbagnano (Diccionario de Filosofia, ad verbum) tiene en él, como en Sexto Empírico, un carácter metódico, suspensivo y dubitativo, con ánimo de resolverse, como dice Montaigne, pero sin poder hacerlo, "por hallarse siempre mi alma en prueba y aprendizaje". Y por último, y para terminar con esto, el escepticismo así entendido, no es sino una de las formas del platonismo, si recordamos cómo Walter Pater asigna a Platón una doble descendencia histórica: la de los grandes dogmáticos idealistas, de Plotino a Hegel, y la de los escépticos que tan legítimamente como aquellos otros pueden encontrarse en tantos diálogos del maestro resueltamente aporéticos.

Con Montaigne, sin embargo, acontece algo semejante a lo que pasa en Kant, que si la razón especulativa no puede rebasar la experiencia sensible, sí en cambio, la razón práctica, la cual se cumple en Montaigne por la vía del estoicismo.

\section{Montaigne estoico}

Como en Vico, ni más ni menos, los sistemas filosóficos están sujetos a continuos corsi e ricorsi. Van y vienen a compás de las circunstancias; tienen, como dicen los italianos, su fortuna.

Con el estoicismo ha habido, como tenía que ser, una evolución semejante. En gran favor el estoicismo antiguo y el estoicismo romano, hasta la época imperial por lo menos (Epicteto y Séneca son del tiempo de Nerón) pasa por un paréntesis de silencio en la edad media cristiana, ya por la dificultad del recurso directo a las fuentes, o lo que es más probable, por su directa oposición con la cosmovisión cristiana en física y metafísica, y en cuanto a la moral, por formar las virtudes cristianas un complejo semejante al de las virtudes estoicas, y por encima de esto, sublimadas en la virtud unificativa de la caridad. Hay que recordar, a este propósito, cómo todavía Epicteto tiene por indignas

25 Essais, II, 12, pp. 350-351, ed. Folio. Página horrorosamente traducida por Juan G. de Luaces, que hace decir a Montaigne lo contrario precisamente de lo que dejó escrito. Ed. Orbis, Barcelona, 1985, p. 246. 
del sabio estoico virtudes tan túpicamente cristianas como la compasión y la misericordia.

Con el Renacimiento, en cambio, recobra actualidad el estoicismo, y tanto más cuanto que entramos en tiempos atormentados, en razón directa de los cuales ha estado siempre la resurrección del estoicismo. Ahora bien, si ha habido alguna época atormentada ha sido sin la menor duda el Renacimiento, donde sobre su estela de gloria literaria, filosófica y científica, está inscrita la violencia, la más salvaje y despiadada, la de las guerras de religión, terminadas al fin ipero después de más de un siglo de horrores! en la paz de Westfalia de 1648.

La resurrección del estoicismo en esta época, en suma, la explica Fortunato Strowski de la siguiente manera:

Los tiempos eran de tal dureza que había que armarse de valor y de fuerza. Ahora bien, una sola de las antiguas éticas, había enseñado victoriosamente el valor de la constancia y el sacrificio en las calamidades públicas y privadas. Su divisa: sustine et abstine, la habían asumido los mejores y más grandes de entre los hombres de antaño. Por ello se habían inmolado Catón, Epicteto y Marco Aurelio. Y puesto que con los tiempos modernos habían vuelto los tiempos de Nerón, había que volver a la misma sabiduría y a los mismos preceptos. El estoicismo asumió de este modo el humanismo por completo, o fue en cualquier caso el único humanismo viable. $^{26}$

Aparte de estas razones extrínsecas, por decirlo así, la dureza y crueldad de los tiempos, había también razones intrínsecas en favor del estoicismo, como era el hecho de que de todos los sistemas de la filosofía antigua, era el menos sospechoso de epicureísmo y de impiedad, y el que guardaba mayor concordancia con la moral cristiana, y en esta apreciación concurrían por igual protestantes y católicos. La primera traducción al francés del Manual de Epicteto fue la de un protestante, Rivaudeau, y la segunda la de un católico, Guillermo de Vair, uno de los altos personajes de la época, jurista, parlamentario, embajador, obispo y gran canciller de Francia. Esto por los traductores; y por los autores que igualmente sintieron la seducción de Epicteto, bastará con citar, amén de los Ensayos de Montaigne, la Manuductio ad philosophiam stoicam de Justo Lipsio, la Filosofia moral de los estoicos de Guillermo de Vair, las Cartas a la princesa Isabel de Descartes, y por último, pero no por cierto lo menor, el Tratado del amor de Dios de san Francisco de Sales, en cuyas obras en general, según dice Fortunato Strowski, “toda la gracia de la belleza helénica está unida a la gracia cristiana”. En lo concerniente a Epicteto, el santo obispo de Ginebra nos ha dejado el siguiente testimonio: 
Con gran emoción vemos a este excelente filósofo hablar a veces de Dios con tanto gusto, celo y sentimiento, que podría tomársele por un cristiano saliendo de una santa y profunda meditación, y en otros pasajes, sin embargo, menciona a la pagana a los dioses. ${ }^{27}$

Nosotros estamos hoy más habituados a este lenguaje, ya que lo divino no era entonces, como lo fue después con el cristianismo, un carácter incompartible del Dios único, sino que se repartía sin dificultad entre el dios supremo y la turbamulta de dioses y diosecillos. A Pascal también, a su tiempo, le impresionó lo que tan frecuentemente aflora en los discursos de Epicteto, que "todo el estudio y el deseo del hombre debe ser el de reconocer la voluntad de Dios y seguirla". ${ }^{28}$

Ahora bien, y para el propósito que aquí y ahora perseguimos, nos bastará concentrarnos en el punto central de la filosofía de Epicteto, resumida toda ella en el Manual, y que podemos apresar sin salir siquiera del primer capítulo:

De las cosas unas están en nuestro poder, y las otras no lo están. En nuestro poder están la opinión, la tendencia, el deseo, la aversión, y en una palabra, todas nuestras operaciones. En nuestro poder, en cambio, no están nuestro cuerpo, la riqueza, la reputación, los altos cargos, y en una palabra, todas las cosas que no son nuestras propias obras. Ahora bien, las cosas que dependen de nosotros son por su naturaleza libres, sin trabas ni impedimentos, mientras que las que no dependen de nosotros son frágiles, esclavas, fácilmente impedibles y dependientes de la voluntad ajena.

Ten presente, por tanto, que si tienes por libres las cosas naturalmente esclavas, y las ajenas como propias, estarás impedido, afligido, turbado, y acusarás a los dioses y a los hombres; mientras que si tienes por tuyo únicamente lo que es tuyo, y por ajeno lo que es realmente ajeno, nadie podrá jamás constreñirte ni ponerte trabas, ni enderezarás a nadie acusación ni reproche, ni harás nada absolutamente contra tu voluntad, ni recibirás daño de nadie, ni tendrás enemigos ni sufrirás daño alguno.

Todo en este discurso está cifrado, como diría nuestro clásico. Es en la edad antigua el evangelio de la libertad interior, a tal punto que, según observa Oldfather, las voces "libre" y "libertad" (eleutheros, eleutheria) aparecen 130 veces en los escritos de Epicteto, o sea seis veces más que en el evangelio cristiano, y dos veces más que en Marco Aurelio. Nadie más que Epicteto, el antiguo esclavo que acabó teniendo, ya liberto, una de las cátedras más ilustres del mundo clásico, estuvo enamorado de la libertad, y éste fue el ideal que transmigró a los humanistas del siglo XVI. Ansiosos como nadie estaban, ellos mismos, de la libertad interior, tan difícil de alcanzar en la época de las

27 Ibid., pp. 132-133.

28 Pascal, Entretien avec $M$. de Saci sur Epictete et Montaigne. 
guerras de religión, cuando hasta la opción religiosa, lo más sagrado de la conciencia humana, acabó por subordinarse al poder del Estado: cuius regio eius religio.

En aquellos hombres debe haber resonado el mensaje de Epicteto, la filosofía de la liberación de aquel riempo, expresada en uno de sus más hermosos diálogos, el De la libertad:

El hombre no sujeto a traba alguna es libre, el que tiene todas las cosas a su mano y a su voluntad... ¿Y quién es el hombre exento de toda traba? El que no desea nada de lo que le es ajeno. ¿Y qué cosas nos son ajenas? Las que no dependen de nosotros, ni en su posesión ni en su desposesión. Nuestro cuerpo, por consiguiente, nos es ajeno, y también la fortuna. ${ }^{29}$

"Esforcémonos por que nuestra felicidad dependa de nosotros" (faisons que notre contentement dépende de nous) dícenos Montaigne en una clara reminiscencia de Epicteto. Y por más que otras muchas puedan sin dificultad detectarse en los Ensayos, nos limitaremos, por su fuerza expresiva, a trasladar el siguiente pasaje:

Hay que tener sí, por cierto, mujer, hijos y bienes, y sobre todo salud en lo posible; mas no apegarnos a todos ellos de manera que de ellos dependa nuestra felicidad. Reservémonos un apartamiento secreto, todo nuestro, donde nos sea posible establecer nuestra verdadera libertad y nuestro principal refugio y soledad. Es en este retiro donde hemos de tener nuestra ordinaria conversación de nosotros con nosotros mismos; discurrir y rér como si estuviéramos sin mujeres, sin hijos ni bienes ni sirvientes, a fin de que, cuando los perdamos, no nos sorprenda su pérdida. Tenemos un alma que puede encerrarse consigo misma y hacernos compañía, y no hay por qué temer que en nuestra soledad podamos estancarnos en tediosa ociosidad.. . Hemos vivido bastante para otros; vivamos para nosotros mismos lo que nos resta de vida... La mayor cosa del mundo es la de saber ser cada uno para sí mismo. ${ }^{30}$

En Descartes igualmente podemos encontrar muchos pasajes escritos en la misma clave, como la tercera máxima de la moral provisoria:

Esforzarme en vencerme a mí mismo antes que a la fortuna, y en mudar mis deseos antes que el orden del mundo, y en general acostumbrarme a creer que no hay nada que esté por completo en nuestro poder sino nuestros pensamientos.

Máxima típicamente estoica, según comenta Strowski, como otros muchos lugares de su correspondencia con la princesa Isabel, entre ellos aquel en que

30 Essais, I, 39, p. 350, ed. Folio: La plus grande chose du monde, c'est de savoir ctre à soi. 
Descartes, hablando de sus achaques, añade, sin embargo, que en nada afectan ellos a su contentamiento íntimo, el cual, dice "no depende sino de mí mismo" (ne dépend que de moi même).

En esta eclosión espléndida del humanismo francés entre los siglos XVI y XVII, hay tres hombres que vivieron, de un extremo al otro de su vida, soberanamente libres: Montaigne, Descartes y Pascal. De los dos primeros salta a la vista, pero aun del tercero, contra lo que a primera vista pudiera parecer, puede predicarse otro tanto, si recordamos su confrontación con Roma, en cosas que no fuesen el dogma puro, con la apelación a Cristo por encima de su vicario: Ad tuum, Domine Iesu, tribunal appello.

En las circunstancias actuales, y cuando apenas estamos emergiendo de la carrera desenfrenada de la nación entera por el poder político, con todas las concupiscencias en él implícitas, me ha parecido oportuno evocar aquellas figuras que se ciernen aún sobre nosotros y que configuran el evangelio de la libertad interior. Los políticos de entonces, Colbert, Richelieu, Mazarino, están muertos y bien muertos, mientras que aquellos otros tres que acabo de evocar, Montaigne, Descartes y Pascal, están hasta hoy tan vivos como en la vida que vivieron, y alumbran con luz indeficiente nuestra vía y destino. 